\title{
Some aspects of the biology and life history of Bothitrema bothi (Monogenea: Bothitrematidae) from the flounder Scophthalmus aquosus (Bothidae) from New Jersey, USA
}

\author{
Sherman S. Hendrix \\ Department of Biology, Gettysburg College, Gettysburg, PA 17325, USA
}

Key words: functional morphology, scanning electron microscopy, oncomiracidium, Bothitrema bothi, cholinergic nerves, microecology, Monogenea, Bothitrematidae

\begin{abstract}
Bothitrema bothi (MacCallum, 1913), a monopisthocotylean monogenean (Bothitrematidae) found on gills and occasionally on the olfactory rosette within the nares of the bothid flounder, Scophthalmus aquosus (Mitchill, 1815), is distributed along the Atlantic coast of the USA from Woods Hole, Massachusetts to Delaware Bay. This study details aspects of the morphology, microecology and biology of the oncomiracidium, juvenile and adult. Adult worms occur almost exclusively between rakers on the first and second gill arches while juveniles occupy secondary gill filaments. Analysis of variance revealed significant arch, side and position effects. Worm attachment and position is maintained largely by suction generated by a circular seal using its 54 radially arranged accessory haptoral sclerotised elements and a marginal valve. A small anterior appendix with two marginal hooks lies dorsal to a deep anteromedian cleft in the haptor, which, together with wall muscles, creates and releases the negative pressure required for attachment. Four pairs of gland openings in the ventrolateral margins of the anterior adhesive area produce secretions for attachment. Operculate eggs with four rounded protuberances and a filament are laid individually at four-minute intervals at $22^{\circ} \mathrm{C}$. Hatching occurs in five days at $20^{\circ} \mathrm{C}$. Oncomiracidia have two pairs of eyes, with the posterior pair fused, show both positive and negative phototaxis and swim at a mean rate of $5.2 \mathrm{~mm} / \mathrm{s}$ at $22^{\circ} \mathrm{C}$. Larvae have a circle of 16 hooks and a pair of hamulus primordia. Other accessory haptoral sclerotised structures arise de novo in juveniles after attachment to the host. These data will help to resolve more clearly the relationships of the Bothitrematidae within the Monopisthocotylea.
\end{abstract}

The Bothitrematidae (Monogenea: Monopisthocotylea) was erected by Bychowsky (1957) for the monotypic species, Bothitrema bothi (MacCallum, 1913) parasitizing gills of the endemic bothid windowpane flounder, Scophthalmus aquosus (Mitchill, 1815), taken in the vicinity of Woods Hole, Massachusetts, USA. Over the past 90 years, little new information was acquired about this obscure species from the mid Atlantic coast of the north-eastern United States. Price (1937) redescribed the species correcting many errors in interpretation of structures made by MacCallum (1913, 1916, 1917). He also assigned it to the Dactylogyridae. Bychowsky (1957) removed B. bothi from the Dactylogyridae and proposed the Bothitrematidae. Beyond mention in general reviews of monogeneans such as those by Sproston (1946) and Yamaguti (1963), a phylogenetic study (Boeger and Kritsky 2001) and in a molecular-based cladogram constructed by Justine et al. (2002) from specimens collected from New Jersey, the only reports concerning $B$. both $i$ were two surveys along the western Atlantic coast. Meyers (1978) reported it in the vicinity of New York Harbor and Hendrix (1994) from New Jersey. Little is know about this species despite its status within the monotypic genus and family. Here, I describe several light-level and scanning electron microscopical features of the egg, oncomiracidium, juvenile and adult including a small hook-bearing anterior appendix associated with the adult haptor. Moreover, data are presented on distribution of $B$. bothi on host gills plus information on cholinergic staining of elements of the nervous system.

\section{MATERIALS AND METHODS}

Scophthalmus aquosus (Mitchill, 1815) were obtained intermittently over several years from groundfish trawl surveys conducted by members of the New Jersey State Department of Environmental Protection, Division of Fish, Game and Wildlife along the Atlantic Ocean off the coastline of central New Jersey. Freshly trawled fishes were decapitated and placed in $10 \%$ formalin within one hour of capture. For the determination of the spatial position of $B$. bothi on the gills, the entire branchial basket was removed from 28 formalin-fixed fish. Individual arches were examined with the aid of a dissecting microscope, and the position of each monogenean specimen was determined. Counts and positions in each third of each gill arch were analysed by Fixed Effects ANOVA using SAS ${ }^{\circledR}$, Version 6. Parasites were identified using both Hendrix (1994) and Price (1937).

For fresh parasite material, fishes were held alive in a shipboard seawater holding tank for the few hours between capture and landing. Immediately after docking, fishes were either bagged individually and placed on ice if moribund or kept

This paper was presented at the 6th International Symposium on Fish Parasites in Bloemfontein, South Africa, 22-26 September 2003. 
alive in a seawater-filled cooler with aeration for transport to Gettysburg College. On arrival, live fishes were placed into a marine aquarium and held at $15^{\circ} \mathrm{C}$ until dissection. Gills of fishes transported on ice were removed within $24 \mathrm{~h}$ of capture and placed in dishes of seawater filtered through a Gelman Acrodisc ${ }^{\circledR}$ syringe filter. Individual arches were cut and examined separately. Most of the worms found were fixed in neutral $10 \%$ formalin for light microscopy. Other worms were rinsed in filtered seawater, fixed in $2.5 \%$ glutaraldehyde buffered with $0.1 \mathrm{M}$ sodium cacodylate or in Karnovsky's fixative and post-fixed in $1.33 \%(\mathrm{w} / \mathrm{v})$ aqueous osmium tetroxide for scanning electron microscopy (SEM). Bothitrema specimens and host gill tissue were dehydrated through a graded ethanol series, critical point dried, mounted on aluminium stubs and coated with gold in a Denton Desk II sputter coater. Specimens were viewed with a JEOL JSM5200 scanning electron microscope at $10 \mathrm{kV}$.

Several living adult $B$. bothi were removed from the gills to crystallizing dishes containing syringe-filtered seawater for egg-laying experiments. Eggs were incubated in the dark at $15^{\circ} \mathrm{C}$ or at $20^{\circ} \mathrm{C}$ until they hatched. Oncomiracidia were studied alive to determine their morphology and to record their swimming speed over a distance of $10 \mathrm{~mm}$.

Several $B$. bothi adults were fixed under moderate pressure in cold $4 \%$ paraformaldehyde for staining cholinergic (ChE) components of the nervous system. The indoxyl acetate method (Bancroft 1967) was used as indirect evidence for the presence of acetylcholine. Controls included the omission of substrate and preincubation for $1 \mathrm{~h}$ in the $\mathrm{ChE}$ inhibitor, eserine sulfate (Sigma) at a final concentration of $1 \times 10^{-3} \mathrm{M}$.

A number of worms were allowed to decay and disintegrate in filtered seawater and then were teased apart or were sonicated and sedimented to release the sclerotised structures. Attempts to digest haptors to release sclerotised structures were largely unsuccessful due to the rapid disintegration of sclerites in the pepsin artificial digestion fluid used (Mo and Appleby 1990).

Because B. bothi was redescribed by Price (1937), only new information on structures is presented here.

\section{RESULTS}

Analysis of variance of the positions of 306 adult and juvenile $B$. bothi on the gill arches of 28 windowpane flounder (Table 1) showed highly significant arch and position effects and a significant side (left versus right hemibranchs) effect (Table 2). Significantly more $B$. bothi were located on the first and second gill arches than on the third and fourth arches. The worms were distributed largely on the central third of the arches compared to the anterior and posterior thirds. However, there was no statistical difference between the number of parasites on the first and second gill arches. Significantly more worms were found on the right arches than the left arches taken as a group. No combinations of arches and position were significantly different. Large adult worms attached to the gill arches proper, primarily between gill rakers, while juveniles were found almost exclusively on the gill filaments. As they mature, they
Table 1. Distribution of 306 adult and juvenile Bothitrema bothi on the gills of Scophthalmus aquosus collected off the New Jersey coastline, USA.

\begin{tabular}{|c|c|c|c|c|c|}
\hline \multirow{2}{*}{ Arch } & \multirow{2}{*}{ Side } & \multicolumn{4}{|c|}{ Gill Section } \\
\hline & & Anterior & Median & Posterior & Total \\
\hline \multirow{2}{*}{ I } & Left & $17^{*}$ & 25 & 12 & 54 \\
\hline & Right & 17 & 27 & 6 & 50 \\
\hline \multirow{2}{*}{ II } & Left & 9 & 25 & 8 & 42 \\
\hline & Right & 21 & 27 & 14 & 62 \\
\hline \multirow{2}{*}{ III } & Left & 7 & 9 & 6 & 22 \\
\hline & Right & 14 & 23 & 8 & 45 \\
\hline \multirow{3}{*}{ IV } & Left & 2 & 6 & 2 & 10 \\
\hline & Right & 4 & 13 & 4 & 21 \\
\hline & Totals & 91 & 155 & 60 & 306 \\
\hline
\end{tabular}

* number of $B$. bothi

Table 2. Summary of fixed effects analysis of variance of Bothitrema bothi position on gills of Scophthalmus aquosus collected off of the New Jersey coastline, USA.

\begin{tabular}{|l|c|c|c|c|}
\hline \multicolumn{1}{|c|}{ Source } & df & $\mathrm{f}$ & $\mathrm{p}$ & signif. \\
\hline Arch (A) & 3 & 10.51 & $<0.001$ & $* * *$ \\
Position (P) & 2 & 15.11 & $<0.001$ & $* * *$ \\
Side (S) & 1 & 5.36 & $<0.03$ & $*$ \\
A* S & 3 & 1.26 & $<0.29$ & $\mathrm{NS}$ \\
A* P & 6 & 0.71 & $<0.65$ & $\mathrm{NS}$ \\
S* P & 2 & 0.08 & $<0.45$ & $\mathrm{NS}$ \\
A* S* P & 6 & 0.48 & $<0.83$ & $\mathrm{NS}$ \\
\hline
\end{tabular}

statistical significance: *significant at the 0.05 level, $* * *$ significant at the 0.001 level, NS - not significant

move from filaments to the arch, clustering mostly between the rakers as they become too large to maintain their positions on the gill filaments. Occasionally, adults are found attached to the rosette in the nares of their host. The adult worms range in length is 1.4 to $2.5 \mathrm{~mm}$ $(\mathrm{n}=6)$ and they have a distinctive anterior adhesive area and haptor. The ventral floor of the broad anterior adhesive area possesses numerous tubercules over its entire surface anterior and lateral to the level of the mouth (Fig. 1). Four pairs of rectangular, pit-like adhesive gland openings are present along the anteroventral margins. A pair of sensory organs is present just anteromedial to the first pair of adhesive gland openings. The subspherical mouth is located on the ventral surface at the posterior margin of the anterior end. The surfaces of the adhesive gland duct openings contain numerous rounded projections that are partially covered by small rod-like structures that may be secretory granules. The anterior adhesive area is extensible and has the ability to expand to about twice its normal width on attaching to a smooth surface such as that of a glass dish. The tegument of the general body surface is smooth.

Bothitrema bothi has a circular haptor armed with a pair of hamuli, U-shaped anterior and posterior sclerites, 

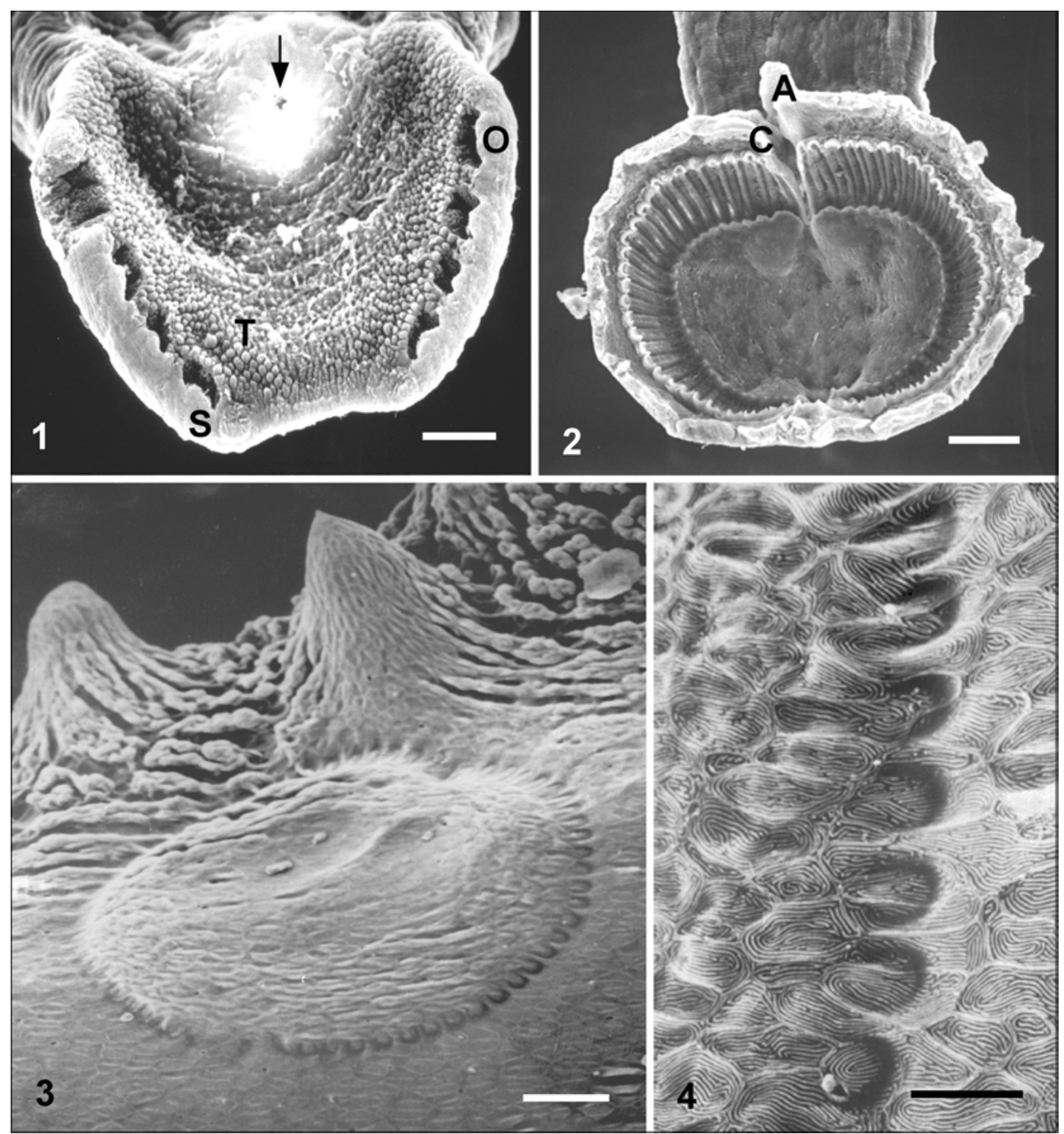

Figs. 1-4. Scanning electron micrographs of adult Bothitrema bothi and Scophthalmus aquosus gill arch. Fig. 1. Anterior adhesive area showing the mouth (arrow) ( $\mathrm{S}$ - sensory organ, $\mathrm{T}$ - tubercules, $\mathrm{O}$ - opening of a ventrolateral secretory gland). Fig. 2. Ventral view of the haptor with its anterior haptoral appendix (A) and a deep anterior haptoral cleft (C). Fig. 3. "Footprint" of $B$. bothi on host gill arch. Fig. 4. View of host gill arch showing marks made by the distal tips of the radially arranged trough-like accessory haptoral sclerotised elements. Scale bars: Fig. $1=0.25$ mm; Figs. 2, $3=50 \mu \mathrm{m}$; Fig. $4=20 \mu \mathrm{m}$.

usually 54 radially arranged trough-like accessory sclerotised elements, a marginal valve, 14 marginal hooklets and a small appendix containing an additional pair of marginal hooklets. Thus, this species has a total of 16 marginal hooklets. The anterior haptoral appendix is located just under the anterior extremity of the haptor and just anterodorsal to a deep cleft in the mid-anterior haptoral wall (Fig. 2). Approximately 54 radially arranged trough-like accessory haptoral sclerotised elements form two semicircles in the ventral wall of the haptor. Living adults have a very active pulsating action in the walls of the haptoral margin flanking the cleft.
Examination by SEM of the slightly raised "footprint" of adult $B$. bothi on gill arches shows a distinct circle of indentations in the host epidermal cells (Fig. 3 ). These indentations are caused by the pressure from the distal tips of the radially arranged accessory haptoral sclerotised elements that, along with the marginal valve, create a seal to help prevent ingress of water (Figs. 4-6). In addition to the circle of sclerotised element marks, a pair of large oval indentations is also present in the anterior part of the "footprint". These are created by underlying pads of the U-shaped anterior accessory sclerite in the wall of the haptor. 

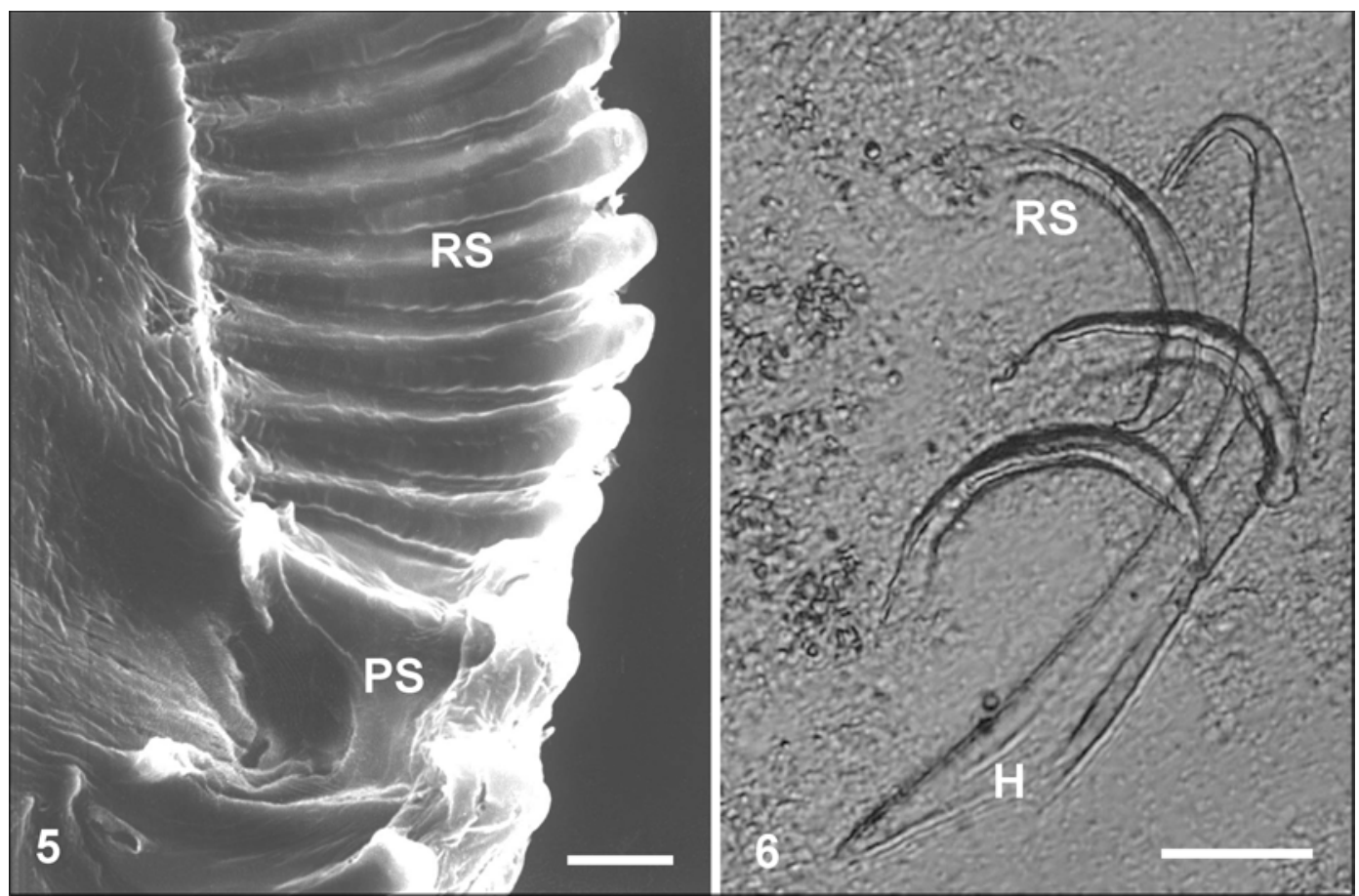

Figs. 5, 6. Micrographs of haptoral accessory sclerites and hamulus of adult Bothitrema bothi. Fig. 5. Close-up of radially arranged supporting trough-like haptoral sclerotised elements (RS) and U-shaped posterior accessory sclerite (PS). Fig. 6. Light micrograph of an isolated hamulus $(\mathrm{H})$ and three trough-like accessory haptoral sclerotised elements (RS) released from a disintegrated adult. Scale bars: Fig. $5=10 \mu \mathrm{m}$; Fig. $6=20 \mu \mathrm{m}$.

The common genital pore is mid-ventral and posterior to the mouth. The sclerotised male copulatory organ (MCO), located proximal to the genital pore, is a curved tube making one complete turn at the proximal end and has a straight distal end with a bevelled tip. The accessory piece of the MCO is straight with an offset at the distal end through which the tube of the copulatory organ passes. The vagina is unsclerotised and was not seen in this study. A single testis is located just posterior to and partially overlapping the ovary. Numerous vitelline gland cells fill the majority of the mid and posterior portions of the body and largely obscure the single intestinal caecum.

Positive staining of cholinergic components appeared as indigo blue to black in both the central ganglion and the peripheral nerves. Cholinergic staining of the cerebral ganglion and pre-pharyngeal commissure was strong as were major nerve tracts leading to the four pairs of anterior adhesive gland openings and to the two anterolateral sensory organs at the tip of the body (Figs. 7, 8). Eserine and substrate-free control slides showed no staining of nervous tissue but some non-specific esterase staining was evident in the wall of the caecum in the eserine control slides. Two major cholinergic nerves enter the haptor with smaller tracts running to the posterior extremity and along the outer periphery of the radially arranged accessory haptoral sclerotised ele- ments (Fig. 9). The latter partially obscure these nerves. However, non-specific esterase staining was still present, associated with each of the marginal hooklets, in eserine control slides (Fig. 10) but not in substrate-free controls.

The cycle of egg assembly takes $4 \mathrm{~min}$ at $22^{\circ} \mathrm{C}$ from entry of the vitelline cells and ovum in the ootype to a completed egg being laid. Once out of the ootype, muscular contractions of the body force an egg anteriorly through the short uterus and out of the common genital pore before another egg cycle begins. Mature eggs are operculate, more or less tetrahedral with rounded protuberances at each corner. The opercular protuberance has the longest dimension. The egg is $100 \mu \mathrm{m}$ long by 70 $\mu \mathrm{m}$ wide. An elongate flexible filament about $200 \mu \mathrm{m}$ long arises from the aboperculate pole, terminating in a small knob at the tip (Fig. 11). The mean operculum width in hatched eggs is $29 \mu \mathrm{m}(\mathrm{n}=18)$ in diameter (Fig. 12). Embryonation to hatching takes 5 days at $20^{\circ} \mathrm{C}$ and 9 days at $15^{\circ} \mathrm{C}$. One of the prominent developmental features is the formation of eyespots, which appeared on day 3 at $20^{\circ} \mathrm{C}$. Triggers for hatching were not studied due to the relatively few eggs $(<50)$ and even fewer oncomiracidia available.

Living oncomiracidia of $B$. bothi are approximately $130 \mu \mathrm{m}$ long by $40 \mu \mathrm{m}$ wide $(\mathrm{n}=18)$ and have a haptor with a circle of 16 flexible larval hooklets. Hooklet 

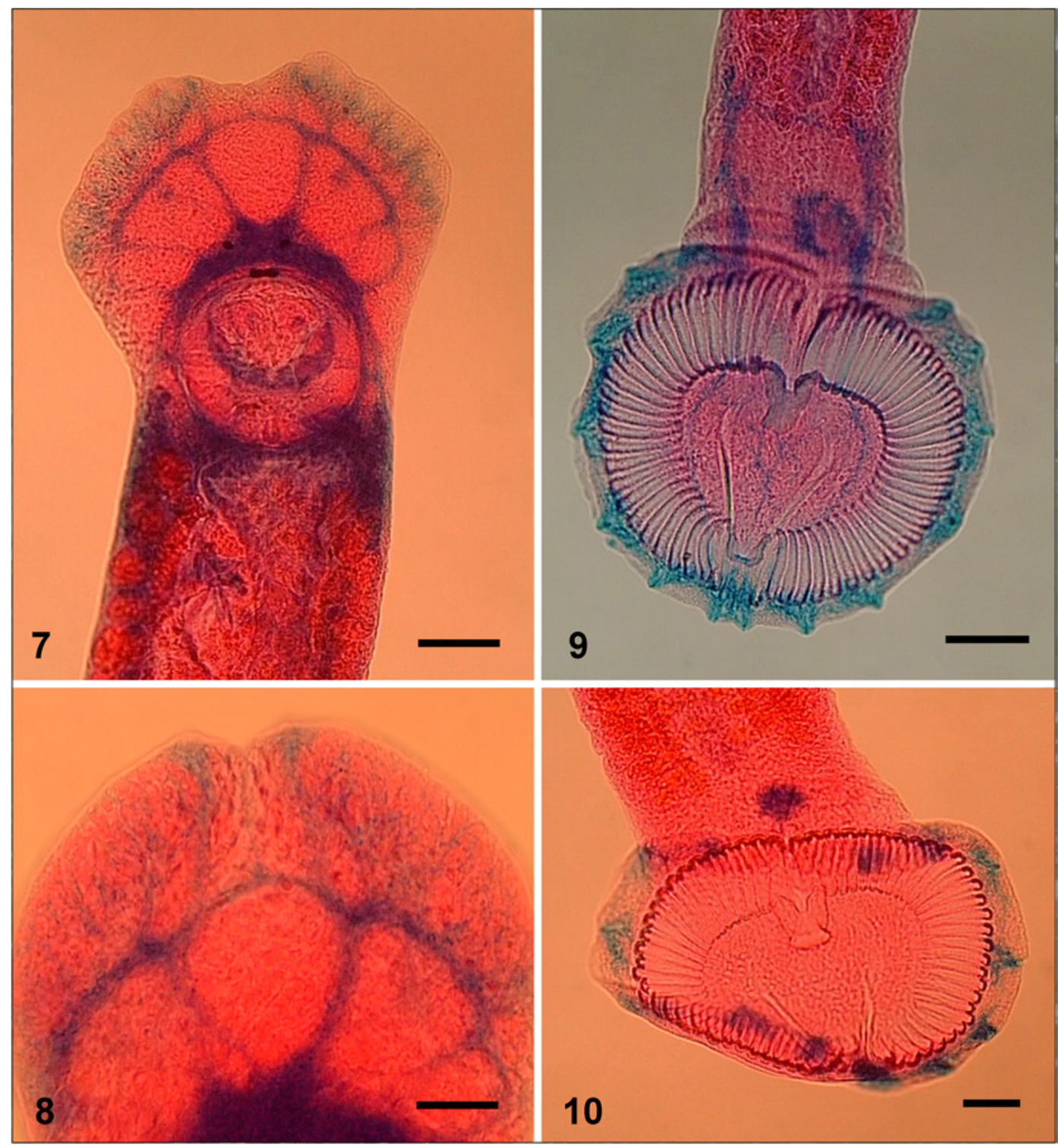

Figs. 7-10. Cholinesterase staining of the Bothitrema bothi nervous system with cholinergic nerves stained in blue. Fig. 7. Staining of the anterior end of an adult. Fig. 8. Close-up of the cholinergic nerves and their association with the anterior sensory structures and adhesive gland openings. Fig. 9. Staining of the posterior portion trunk and the haptor. Fig. 10. Eserine control slide of the haptor showing non-specific esterase stain associated with the marginal hooklets. Scale bars: Figs. 7, 9, $10=50 \mu \mathrm{m}$; Fig. $8=40 \mu \mathrm{m}$.

measurements include: total length 15-16 $\mu \mathrm{m}$, blade length $4.8 \mu \mathrm{m}$, shaft length $10.2 \mu \mathrm{m}$, toe length $3.5 \mu \mathrm{m}$, and domus length $7.2 \mu \mathrm{m}(\mathrm{n}=16)$. The distal tip of the flexible hooklet shaft has a small knob. Two pairs of prominent eyes, three zones of ciliated epidermal cells, ventromedial mouth, round pharynx $18 \mu \mathrm{m}$ in diameter $(\mathrm{n}=4)$, and a short sac-like caecum are also present (Fig. 13). Several pairs of glands are located lateral to the pharynx and have ducts that lead to the anterior tip of the larva. A pair of thin, curved, blade-like structures (presumed hamuli) lie just anterolateral to the haptor in the hind body. The main excretory ducts empty into lateral excretory bladders. The flame bulbs and excretory duct pattern were not fully observed in this study, so no flame bulb pattern is given. There was no evidence of a terminal globule at the posterior tip of the larva. The two pairs of anterodorsal eyes are comprised of pigment cups and crystalline lenses. The smaller anterior pair has pigment cups directed posterolaterally while the larger posterior pair are fused and have their pigment cups directed anterolaterally (Fig. 14). 

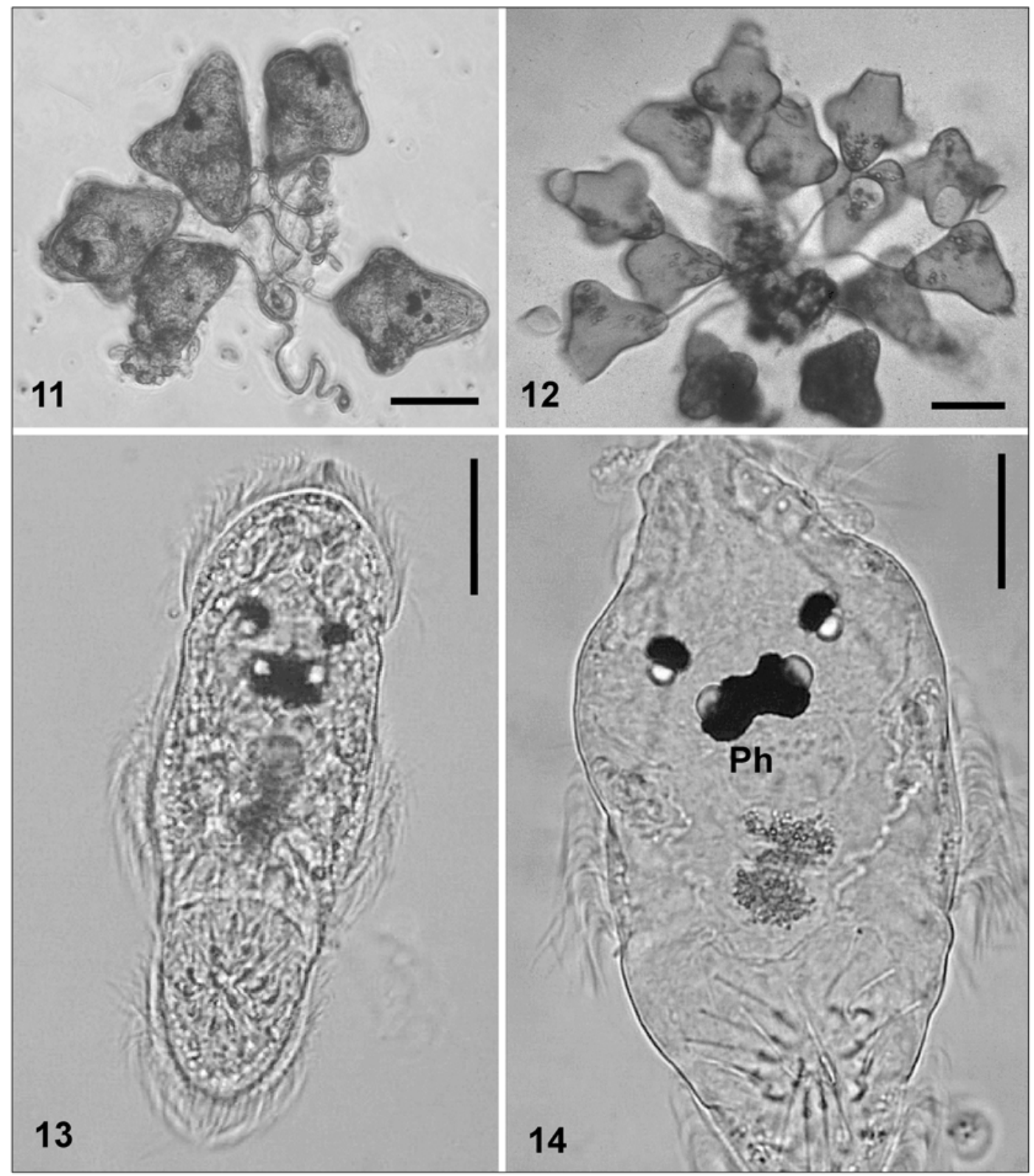

Figs. 11-14. Eggs and oncomiracidia of Bothitrema bothi; light micrographs. Fig. 11. Embryonated eggs with filaments and distal knobs. Fig. 12. Hatched eggs with opercula. Fig. 13. Living oncomiracidium with three zones of ciliated epidermal cells and two pairs of eyes, with the posterior pair fused. Fig. 14. Slightly flattened living oncomiracidium with a round pharynx (Ph) and a circle of 16 larval hooklets. Scale bars: Figs. $11,12=50 \mu \mathrm{m}$; Fig. $13=30 \mu \mathrm{m}$; Fig. $14=10 \mu \mathrm{m}$.

When oriented with a single beam of light, oncomiracidia less than $12 \mathrm{~h}$ old have a mean swimming speed of $5.2 \mathrm{~mm} / \mathrm{s}$ away from the light source with a range of $3.7-6.3 \mathrm{~mm} / \mathrm{s}$ measured over a $10 \mathrm{~mm}$ course at a temperature of $22^{\circ} \mathrm{C}(\mathrm{n}=50$ trials). The larvae swim with a rotating helical pattern along their longitudinal axis in a relatively straight line using their three distinct bands of ciliated epidermal cells for propulsion. The larvae exhibit a negative phototaxis when a horizontal beam of light illuminates the dish. Other behaviours were not studied.
After attachment to its host, the hamuli enlarge followed by additional structures that arise de novo in the juvenile haptor (Figs. 15-17). These include both anterior (Fig. 18) and posterior U-shaped accessory sclerites and the radially arranged trough-like accessory haptoral sclerotised elements plus the marginal valve containing 14 of the 16 marginal hooklets. The small anterior haptoral appendix contains the remaining pair of marginal hooklets that appear to migrate to their adult position near its distal tip. 

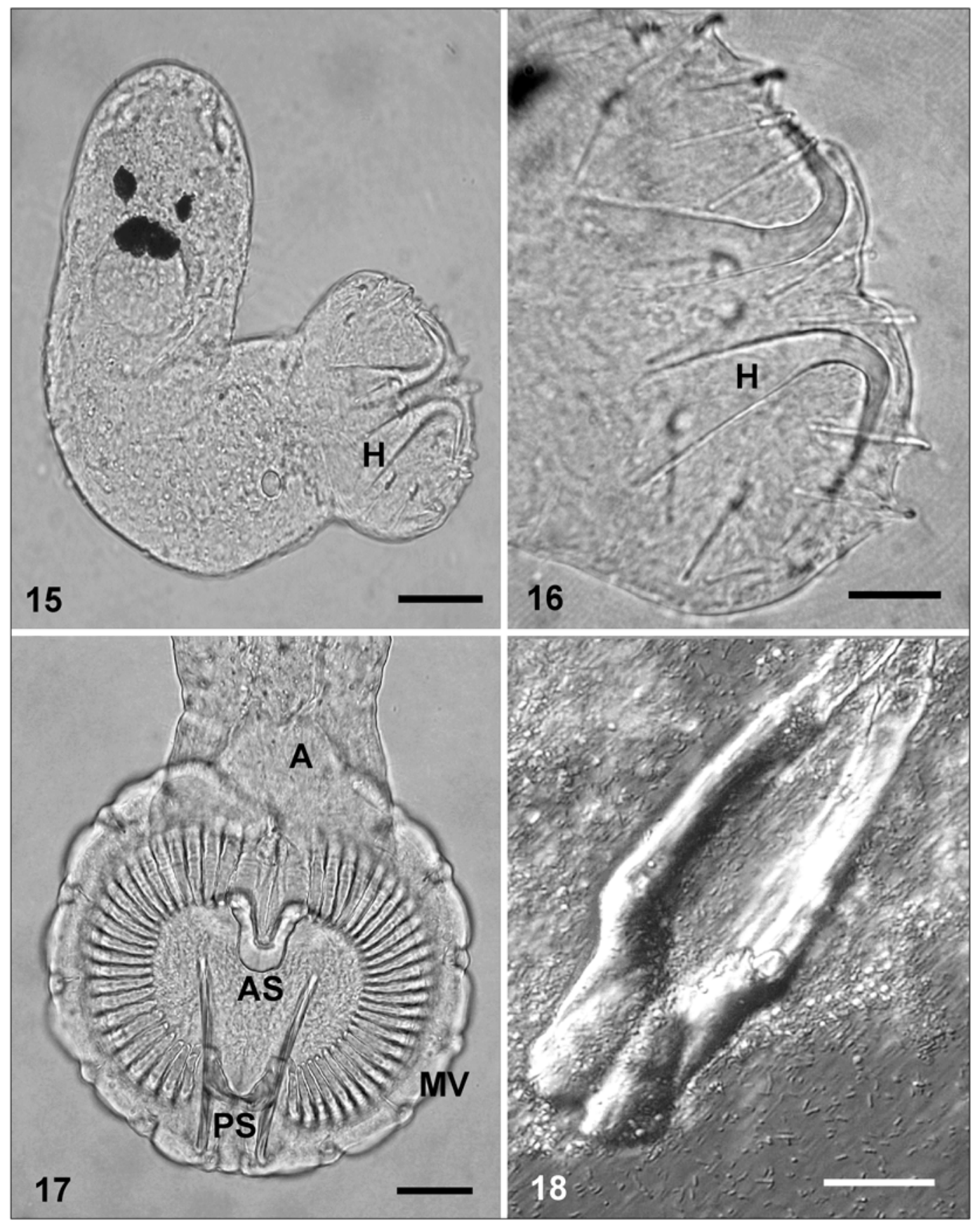

Figs. 15-18. Young juvenile Bothitrema bothi from gills of Scophthalmus aquosus and isolated anterior U-shaped haptoral sclerite; light micrographs. Fig. 15. Young recently attached live juvenile from the gills, with the developing hamuli $(H)$ in the newly formed haptor. Fig. 16. Close-up of the haptor with hamuli $(\mathrm{H})$ of a recently attached juvenile. Fig. 17. The haptor of an older live juvenile with numerous radially arranged accessory haptoral sclerotised elements, a pair of hamuli, anterior (AS) and posterior (PS) U-shaped accessory sclerites, marginal valve (MV) and anterior haptoral appendix (A); dorsal view. Fig. 18. An isolated U-shaped anterior accessory sclerite from a haptor of an adult Bothitrema bothi allowed to disintegrate in seawater; ventral view. Scale bars: Fig. $15=25 \mu \mathrm{m}$; Fig. $16=10 \mu \mathrm{m}$; Fig. $17=40 \mu \mathrm{m}$; Fig. $18=20 \mu \mathrm{m}$.

\section{DISCUSSION}

Although known in the literature for 90 years, Bothitrema bothi is an obscure and poorly known monopisthocotylean monogenean. It was first described by MacCallum (1913) as Acanthocotyle bothi taken from gills of the bothid flounder, Scophthalmus aquosus, from the vicinity of Woods Hole, Massachusetts, USA. His original description was incomplete and contained several errors of interpretation, including the number of intestinal caeca, the number of testes and the location of 
the common genital pore. When he subsequently attempted to correct some of these errors, he maintained many of them, including the nature of the numerous radially arranged accessory sclerotised elements in the haptor, number of testes, and nature of the caecum (MacCallum 1916, 1917). Price (1937) corrected most of the errors in his redescription of the species. Brinkmann (1940) apparently unaware of Price's work recognized that $B$. bothi did not belong to the genus Acanthocotyle. However, he did not suggest a new placement due to the inaccuracies in the original descriptions. Bychowsky (1957) erected the new family Bothitrematidae to accommodate $B$. bothi arguing against Price's (1937) inclusion of this species as an aberrant member of the Dactylogyridae. Bychowsky (1957) suggested that having 16 marginal hooklets was, by itself, enough to exclude this genus from the Dactylogyridae, but he also mentioned the difference in which the haptor functions in attachment to the host.

No previous author working with adult $B$. bothi has described or mentioned the small haptoral appendix at its anterior extremity. It is present on the ventral surface just anterodorsal to the haptor and contains a pair of marginal hooklets. Because of its small size and position, the appendix is difficult to see in light microscopy and is easily overlooked. The appendix is located just dorsal to the cleft in the anteromedial wall of the haptor and can partially cover it helping to create a seal at this point in the haptor. The slightly raised "footprint" on gill arches suggests that a negative pressure in the haptor is the main mechanism for attachment. The haptor is held in place with the aid of the numerous radially arranged supporting haptoral sclerotised elements and a marginal valve creating a peripheral seal. This suction cup-like seal may be formed and released by coordination of the appendix and pumping action of the anterior haptoral cleft walls allowing water to be either removed or introduced under the haptor via the anterior cleft.

After larval attachment to the gills, the hamuli enlarge the earliest, followed by the de novo appearance of the appendix, radially arranged accessory haptoral sclerotised elements, marginal valve and associated anterior and posterior U-shaped sclerites in older juveniles. Bychowsky (1957) predicted correctly that these structures would arise de novo after attachment.

Distribution of $B$. bothi on gills of S. aquosus was not random. Larger adult worms were found almost exclusively on the first two gill arches typically between rakers where they had a relatively flat surface onto which to cling. Juvenile worms were found on gill filaments rather than on the gill arch and rakers. Growth of the worms and the necessity for a flat surface for adhesion forces them to move from filaments to the rakers because filaments with their limited width no longer provide an adequate microhabitat. Significantly more worms were found on the first two arches than the third or fourth arch and on the right or upper arches than the left or lower arches in these flounders. Numerous authors (for example Suydam 1971, Buchmann 1989, El Hafidi et al. 1998, and Dzika 1999) have studied the distribution and the site specificity of Monogenea on gill arches and have given varying results with one or more species of monogenean present. No other species of monogenean was encountered on gills of $S$. aquosus in this study.

Cholinergic staining of the nervous system of $B$. bothi conforms to the basic orthogonal pattern described for several other monogeneans (Halton and Jennings 1964, Halton and Morris 1969, McKay et al. 1991, Cable et al. 1996, Halton et al. 1998). Nerve tracts leading from the central ganglia to the anterior adhesive openings suggest that the cholinergic system plays a role in releasing their secretions. The cholinergic tracts into the haptor suggest further that this system may also play a role in coordinating the parasite's attachment. Other components of the nervous system need to be studied to further clarify the relative roles of each type in the functioning of the various parasite systems.

The assembly of eggs is a complex process involving the release of an oocyte and several vitelline cells into the ootype. Once the ootype is filled, the initial vigorous movement of the contents is gradually slowed as the shell forms. The egg is then forced anteriorly and out of the genital pore by contractions of the body-wall musculature. The egg-forming process and timing appears to be similar to that reported for Entobdella soleae Van Beneden et Hesse by Kearn (1985). The eggs of $B$. bothi, originally described as triangular and flat by MacCallum (1913), are more or less tetrahedral with prominent protuberances. Each egg has an operculum at one pole and an elongate flexible filament with small terminal knob extending from the opposite pole. Kearn (1986) mentioned that eggs of several species of monogeneans of bottom-dwelling flatfishes are roughly tetrahedral in shape. Eggs laid by a single individual in dishes of seawater tended to have their filaments entangled. Whether this entanglement happens to attach them to the host gills or whether the terminal knob allows eggs to attach to sand grains is unknown. Kearn (1986) summarised the possible role of egg filaments in the dispersal of monogeneans. The chemical nature of the opercular seal is unknown.

The oncomiracidium of $B$. bothi has a typical distribution of ciliated cells in three regions: anterior, medial and posterior (Whittington et al. 2000). Due to the small number of larvae available, the number of ciliated cells in each region was not determined in this study. Two pairs of eyes, with the posterior pair fused, and single sac-like intestine in both oncomiracidium and adult are also found in the Sundanonchidae and Tetraonchidae (Boeger and Kritsky 2001). The thin sclerotized structures found associated with the larval haptor are considered primordia of the hamuli which appear early 
in post-larval development (Llewellyn 1963). Oncomiracidia showed a directional response to a beam of light by swimming in a straight line with rotation along the longitudinal axis. This swimming behaviour in $B$. bothi is contrary to that of the few monopisthocotylean oncomiracidia with two pairs of pigment-shielded eyes studied to date, which do not appear to rotate while swimming (Whittington et al. 2000).

Although new information is presented for some aspects of the biology and several stages in the life cycle, much remains to be learned about $B$. bothi particularly at the ultrastructural level of this unusual monogenean. Studies are underway to determine the morphology and the type of spermatozoa plus details on other aspects of the biology.

Acknowledgements. This work was supported in part by faculty research and travel grants from Gettysburg College. I thank my students for preliminary work with SEM and to my colleague, Dr. Kazuo Hiraizumi, for aid with the statistical analyses. Special thanks go to Donald M. Byrne, Principal Fisheries Biologist, New Jersey Department of Environmental Protection and his crews for collection of fishes. I also wish to thank the organizers of the Sixth International Symposium on Fish Parasites for inviting me to present this work at the University of the Free State, Bloemfontein, South Africa and two anonymous reviewers for their helpful comments.

\section{REFERENCES}

BANCROFT J.D. 1967: Histochemical Techniques. Second Edition. Butterworths, London, 348 pp.

BOEGER W.A., KRITSKY D.C. 2001: Phylogenetic relationships of the Monogenoidea. In: D.T.J. Littlewood and R.A. Bray (Eds.), Interrelationships of the Platyhelminthes. Taylor and Francis, London, pp. 92-102.

BRINKMANN A. 1940: Contribution to our knowledge of the monogenetic trematodes. Bergens Mus. Arbok Naturvit. Rekke 1: 1-117.

BUCHMANN K. 1989: Microhabitats of monogenean gill parasites on European eel (Anguilla anguilla). Folia Parasitol. 36: 321-329.

BYCHOWSKY B.E. 1957: Monogenetic Trematodes: Their Systematics and Phylogeny. English translation edited by W.J. Hargis, Jr., 1961. American Institute of Biological Sciences, Washington D.C., 627 pp.

CABLE J., MARKS N.J., HALTON D.W., SHAW C., JOHNSTON C.F., TINSLEY R.C., GANNICOTT A.M. 1996: Cholinergic, serotoninergic and peptidergic components of the nervous system of Discocotyle sagittata (Monogenea: Polyopisthocotylea). Int. J. Parasitol. 26: 1357-1367.

DZIKA E. 1999: Microhabitats of Pseudodactylogyrus anguillae and P. bini (Monogenea: Dactylogyridae) on the gills of large-size European eel Anguilla anguilla from Lake Gaj, Poland. Folia Parasitol. 46: 33-36.

El HAFIDI F., BERRADA-RKHAMI O., BENAZZOU T., GABRION C. 1998: Microhabitat distribution and coexistence of Microcotylidae (Monogenea) on the gills of the striped mullet Mugil cephalus: chance or competition? Parasitol. Res. 84: 315-320.

HALTON D.W., JENNINGS J.B. 1964: Demonstration of the nervous system in the monogenetic trematode Diplozoon paradoxum Nordmann by the indoxyl acetate method for esterases. Nature 202: 510-511.

HALTON D.W., MAULE A.G., MAIR G.R., SHAW C. 1998: Monogenean neuromusculature: some structural and functional correlates. Int. J. Parasitol. 28: 1609-1623.

HALTON D.W., MORRIS G.P. 1969: Occurrence of cholinesterase and ciliated sensory structures in a fish gill-fluke, Diclidophora merlangi (Trematoda: Monogenea). Z. Parasitenkd. 33: 21-30.

HENDRIX S.S. 1994: Platyhelminthes: Monogenea. In: Marine flora and fauna of the eastern United States. NOAA Tech. Rep. NMFS 121, 107 pp.
JUSTINE J.-L., JOVELIN R., NEIFAR L., MOLLARET I., LIM L.H.S., HENDRIX S.S., EUZET L. 2002: Phylogenetic positions of the Bothitrematidae and Neocalceostomatidae (monopisthocotylean monogeneans) inferred from 28S rDNA sequences. Comp. Parasitol. 69: 20-25.

KEARN G.C. 1985: Observations on egg production in the monogenean Entobdella soleae. Int. J. Parasitol. 15: 187194.

KEARN G.C. 1986: The eggs of monogeneans. Adv. Parasitol. 25: 175-273.

LLEWELLYN J. 1963: Larvae and larval development of monogeneans. Adv. Parasitol. 1: 287-326.

MacCALLUM G.A. 1913: Notes on four trematode parasites of marine fishes. Zentralbl. Bakteriol. Parasitol. 70: 407416.

MacCALLUM G.A. 1916: Acanthocotyle bothi $\mathrm{n}$. sp. Zentralbl. Bakteriol. Parasitol. 77: 486-487.

MacCALLUM G.A. 1917: Some new forms of parasitic worms. Zoopathologica 1: 45-75.

McKAY D.M., HALTON D.W., MAULE A.G., JOHNSTON C.F., SHAW C., FAIRWEATHER I. 1991: Putative neurotransmitters in two monogeneans. J. Helminthol. 28: 75-81.

MEYERS T.R. 1978: Prevalence of fish parasitism in Raritan Bay, New Jersey. Proc. Helminthol. Soc. Wash. 45: 120128.

MO T.A., APPLEBY C. 1990: A special technique for studying haptoral sclerites of monogeneans. Syst. Parasitol. 17: 103-108.

PRICE E.W. 1937: North American monogenetic trematodes. I. The superfamily Gyrodactyloidea. J. Wash. Acad. Sci. 27: 114-164.

SPROSTON N. 1946: A synopsis of the monogenetic trematodes. Trans. Zool. Soc. Lond. 25: 185-600.

SUYDAM E.L. 1971: The micro-ecology of three species of monogenetic trematodes of fishes from the Beaufort-Cape Hatteras area. Proc. Helminthol. Soc. Wash. 38: 240-246.

WHITTINGTON I.D., CHISHOLM L.A., ROHDE K. 2000: The larvae of Monogenea (Platyhelminthes). Adv. Parasitol. 44: 139-232.

YAMAGUTI S. 1963: Systema Helminthum. IV. Monogenea and Aspidocotylea. Interscience, New York, 699 pp.

Accepted 26 April 2004 